\title{
Os desafios da Educação no Campo em tempos de Cibercultura
}

\author{
Los desafíos de la Educación en el Campo en tiempos de Cibercultura \\ The challenges of field education in times of cyberculture
}

\author{
Kety da Costa Maciel $^{1}$ \\ Paula Fernanda Rodrigues Brum² \\ Maria Silvana Gritti ${ }^{3}$
}

\begin{abstract}
Resumo
O presente artigo visa apresentar uma pesquisa realizada em uma escola municipal localizada em um Assentamento Rural da Reforma Agrária, no município de Pedras Altas, no Rio Grande do Sul. O estudo foi realizado com alunos do $9^{\circ}$ ano do Ensino Fundamental. A metodologia utilizada foi exploratória e para realizar a investigação utilizamos a aplicação de uma atividade de produção de relato no Google Drive, aplicativo disponível no Google. Este aplicativo foi utilizado visto que a pesquisa também tem o objetivo de aproximar os alunos das ferramentas tecnológicas no contexto educacional. A pesquisa busca apontar como os discentes percebem a escola a que pertenceram durante o Ensino Fundamental. Como fundamentação teórica nos baseamos nos estudos de Caldart (2002), Gritti (2003) e Santaella (2013), Santos (2012). Desta forma a pesquisa buscou entender, através da visão dos discentes, como se dá o processo de ensino e aprendizagem da escola do campo, bem como se estas têm acesso às tecnologias digitais no processo de ensino, visto que hoje elas fazem parte do cotidiano das pessoas. Destarte, entende-se a necessidade de utilizar as tecnologias digitais também para o ensino e aprendizagem dos alunos do campo, embora ainda existam inúmeras barreiras de acesso. Desta forma, percebeu-se a necessidade de uma proposta de ensino mais direcionada ao aluno do campo aliada ao uso das tecnologias digitais na proposta de ensino.
\end{abstract}

Palavras-Chave: Educação do campo; Currículo; Tecnologias Digitais.

\section{Resumen}

El presente artículo pretende presentar una investigación realizada en una escuela municipal ubicada en un Asentamiento Rural de la Reforma Agraria, en el municipio de Pedras Altas, en Rio Grande do Sul. El estudio fue realizado con alumnos del $9^{\circ}$ año de la Enseñanza Fundamental. La metodología utilizada fue exploratoria y para realizar la investigación utilizamos la aplicación de una actividad de producción de relato en Google Drive, aplicación disponible en Google. Esta aplicación fue utilizada ya que la investigación también tiene el objetivo de aproximar a los alumnos de las herramientas tecnológicas en el contexto educativo. La investigación busca apuntar como los alumnos perciben la escuela a la que pertenecieron durante la Enseñanza Fundamental. Como fundamentación teórica nos basamos en los estudios de Caldart (2002), Gritti (2003) y Santaella (2013), Santos (2012). De esta forma la investigación buscó entender, a través de la visión de los discentes, cómo se da el proceso de enseñanza y aprendizaje de la escuela del campo, así como si éstas tienen acceso a las tecnologías digitales en el proceso de enseñanza, ya que hoy ellas forman parte del cotidiano de las cotidianas personas. Por lo tanto, se entiende la necesidad de utilizar las tecnologías digitales también para la enseñanza y el aprendizaje de los alumnos del campo, aunque todavía existen numerosas barreras de acceso. De esta forma, se percibió la necesidad de una propuesta de enseñanza más orientada al alumno del campo aliada al uso de las tecnologías digitales en la propuesta de enseñanza.

\footnotetext{
${ }^{1}$ Pós-graduada em Supervisão Escolar- Faculdade de Ciências Sociais de Florianópolis; SC; Brasil; ketycosta73@gmail.com

2 Mestranda em Educação; Unipampa - Campus Jaguarão; RS; Brasil; fernandabrum42@ yahoo.com.br

${ }^{3}$ Doutora em Educação pelo Programa de Pós-Graduação em Educação da Universidade Federal do Rio Grande do Sul- UFRGS; Porto Alegre; RS; Brasil; silvanagritti@gmail.com
} 
Palabras claves: Educación del campo; plan de estudios; Tecnologías Digitales.

\begin{abstract}
The present article aims to present a research carried out in a municipal school located in a Rural Settlement of Agrarian Reform, in the municipality of Pedras Altas, in Rio Grande do Sul. The study was carried out with students of the 9th year of Elementary School. The methodology used was exploratory and to carry out the research we used the application of a reporting activity in Google Drive, an application available on Google. This application was used since the research also aims to bring students closer to the technological tools in the educational context. The research seeks to point out how the students perceive the school to which they belonged during Elementary School. As a theoretical basis we base ourselves on studies by Caldart (2002), Gritti (2003) and Santaella (2013), Santos (2012). In this way the research sought to understand, through the view of the students, how the teaching and learning process of the rural school is given, as well as if they have access to digital technologies in the teaching process, since today they are part of the everyday life of people. This means the need to use digital technologies also for the teaching and learning of rural students, although there are still a number of access barriers. In this way, it was perceived the need of a proposal of education more directed to the student of the field allied to the use of the digital technologies in the proposal of education.
\end{abstract}

Keywords: Field education; Curriculum; Digital Technologies.

\title{
1. Introdução
}

Atualmente os estudos sobre a educação no campo cresceram muito, impulsionados principalmente pelos movimentos sociais do campo. Embora haja políticas educacionais voltadas para a educação no campo, ainda parece haver uma negação desses direitos e uma invisibilidade da população do campo. Dentre educadores e movimentos sociais que atuam na educação no campo entende-se que é necessário novos projetos educacionais que realmente atendam as particularidades do meio rural. Um ensino que prepare os jovens para futuramente atuarem nas áreas rurais. Porém, esse novo projeto de educação para o campo, valorizando suas identidades, culturas e especificidades ainda é um grande desafio.

Devido aos grandes avanços ocorridos tanto no campo quanto nas cidades, provocando consideráveis mudanças nas áreas de produção e organização social, as pessoas acabam construindo novas relações, tanto pessoais como com o ambiente em que vivem.

A partir desse contexto surgem muitos questionamentos quanto ao projeto educacional a ser construído nas comunidades rurais, diante das transformações que ocorrem nestes espaços. Alguns veem essas transformações como um distanciamento das origens culturais, descaracterizando esses grupos. Por outro lado, é importante considerar que estes grupos precisam evoluir, contudo sem perder sua identidade.

Desta forma, partindo do contexto educacional nas escolas do campo é relevante que estes tenham oportunidades de ensino igualitárias, que contemplem os avanços do mundo 
contemporâneo, sem perder a identidade rural. Novos projetos educativos precisam estar conectados com o desenvolvimento das comunidades, para que os discentes atuem na transformação social e produzam novos conhecimentos voltados para o local em que estão inseridos.

Nessa premissa, torna-se relevante repensar as práticas educativas que são hoje aplicadas ao aluno da escola do campo, refletindo acerca das concepções políticas e pedagógicas que compõem o currículo escolar, permitindo produzir práticas contextualizadas e comprometidas com o desenvolvimento do campo. Conforme Caldart

A Educação do Campo não cabe em uma escola, mas, a luta pela escola tem sido um de seus traços principais: porque a negação do direito à escola é um exemplo emblemático do tipo de projeto de educação que se tenta impor aos sujeitos do campo; porque o tipo de escola que está ou nem está mais no campo tem sido um dos componentes do processo de dominação e de degradação das condições de vida dos camponeses (CALDART, 2004, p.12).

Entende-se que a educação oferecida aos alunos do campo não está voltada para suas características ou necessidades, há uma discordância do sistema educacional quando trata-se de uma educação do campo e para o campo. A educação precisa passar por uma reavaliação e reestruturação dos currículos escolares, para uma definição de metas, ou seja, o currículo precisa ser analisado com um olhar dinâmico e reflexivo.

É importante encontrar novas formas de ensino para atender aos alunos inseridos no campo, pois a área educacional vem sofrendo diversas transformações. De acordo com Molina

\begin{abstract}
Os sujeitos coletivos que lutam pela terra e pela educação, demandam das instituições formadoras uma transformação nas estratégias de socialização e produção de conhecimento [...] trazendo seus saberes e fazeres para dialogar. Assim, para que essa transformação aconteça também é necessário que os docentes que atuam com estes sujeitos estejam preparados para ofertar uma educação que contemple às necessidades da vida no campo. (MOLINA, 2012, p. 243)
\end{abstract}

Desta forma, entende-se que as políticas educacionais para a educação no campo ainda não estão atendendo às especificidades dessa demanda, necessitando assim serem de fato efetivadas para alcançarem seus objetivos.

\title{
2.Fundamentação Teórica
}

A educação integra-se ao cenário de preocupações sociais e incertezas. As conquistas estão expressas na constituição de 1988 e parcialmente na LDB. Muito foi alcançado, porém com o passar do tempo, a frustração ocupou o lugar da esperança pela resistência e pela defesa dos privilégios por parte das classes dominantes. A educação do campo carrega profundas marcas de exclusão nesse cenário quando é orientada a seguir um currículo de Educação Básica com propostas pedagógicas que trabalha em contrapartida aos anseios da 
maioria, não oferecendo subsídios para o viver no campo, apresentando somente a vida urbana como possível meio de atingir os objetivos futuros, provocando assim o êxodo rural. De acordo com o censo agropecuário de 2017 houve uma redução de 1,5 milhão de pessoas nos estabelecimentos rurais em relação ao ano de 2006, confirmando essa migração da zona rural para a zona urbana. Esse dado vem ao encontro também com a assertiva de que a escola que temos no campo não prepara as crianças nem para o mundo urbano nem para o mundo do campo. Segundo Arroyo, Caldart e Molina

a educação não fica apenas na denúncia do silenciamento; ela destaca o que há de mais perverso nesse esquecimento: o direito à educação que vem sendo negado à população trabalhadora do campo. É curioso constatar que desde o início da década de 80 foi se afirmando na sociedade brasileira o reconhecimento da educação com direito humano [...] Entretanto, esse grito não chegou ao campo. (ARROYO, CALDART e MOLINA, 2004, p. 9)

O êxodo rural e propostas pedagógicas excludentes não são os objetivos da Educação do Campo. A intenção da Educação escolar não é ajustar conteúdos, mas sim formar uma identidade coletiva, afirmando o diálogo e a oportunidade de problematizar e articular soluções para os desafios diários da educação do campo.. O calendário escolar proposto para a educação do campo, assim como o currículo, não dialogam com a realidade vivenciada pelos educandos de escolas do campo, embora com lei sancionada. De acordo com a Resolução no 1 , de 03/04/2002, no seu artigo $\mathrm{n}^{\mathrm{o}} 7$, afirma que

\footnotetext{
é de responsabilidade dos respectivos sistemas de ensino, por meio de seus órgãos normativos, regulamentar as estratégias específicas de atendimento escolar do campo e a flexibilização da organização do calendário escolar, salvaguardando, nos diversos espaços pedagógicos e tempos de aprendizagem, os princípios da política e da igualdade.
}

$\mathrm{Na}$ maioria das situações não há discernimento por parte dos órgãos competentes em aplicar a lei no lugar e momentos certos. Com isso os alunos do campo sentem-se excluídos do processo educacional, pois seus saberes prévios e suas vivências não são consideradas quando organizadas as propostas e o calendário anual, limitando também o docente em suas práticas. O trabalho educativo do "[...] educador do campo é aquele que contribui com o processo de organização do povo que vive no campo. (MOLINA, 2002, p.38 )

Muitas escolas do campo ainda têm sido pensadas a partir do modelo educacional disponibilizado para a zona urbana, desconsiderando as características do mundo rural. Cabe ressaltar que não se faz aqui a defesa de uma escola "diferente" para as famílias do campo, mas sim uma escola que atenda às especificidades das famílias localizadas no campo. Segundo Caldart (2004, p. 10) "campo é um lugar, seus trabalhadores também têm direito de ter a escola em seu próprio lugar e a ser respeitados quando nela entram e não expulsos dela 
pelo que são". Parte desse processo provém da negação de produção cultural, política e social, sofrendo influência do capitalismo que persiste em entender as comunidades rurais como locais subdesenvolvidos. Destarte, a organização do currículo das escolas do campo não aprofunda o saber escolar e os saberes produzidos pelos alunos.

Segundo Gritti (2003, p. 133) “o currículo reflete valores dominantes na sociedade. É a partir desses valores e dos interesses dominantes que o currículo é instituído e organizado". Assim, entende-se que o mesmo currículo que contempla a educação urbana está sendo utilizado para atender a demanda de alunos da educação rural. $\mathrm{O}$ ensino restringe-se a cumprir determinações das Secretarias de Educação, ao invés de integrar o aluno no contexto do campo.

Um currículo distanciado da realidade acaba contribuindo para que os sujeitos neguem sua condição rural e percam um pouco da sua identidade. Ainda na visão de Gritti

\begin{abstract}
O homem rural não vê valor e dignidade no trabalho que realiza, porém tem interesse pela vida das plantas e animais; logo, cabe à escola manter tal interesse e continuar desenvolvendo-o. A escola impõe ao trabalhador rural uma concepção negativa de si próprio; ele nunca é o centro das atenções, antes, prioritariamente, é a vida das plantas e dos animais. Pressupõe que o conhecimento próprio do agricultor não serve para conservar e melhorar sua vida e o espaço no qual vive. (GRITTI, 2003, p.147)
\end{abstract}

Neste sentido, ressaltamos também que a educação no campo necessita ser direcionada aos alunos do campo, porém contemplando ainda os avanços tecnológicos a que a sociedade contemporânea vive atualmente. Consoante a isso, é relevante considerar a participação dos docentes frente à proposta da concepção de um currículo que produza efeitos na vida dos alunos, considerando a diversidade de sujeitos e práticas culturais, criando espaços de diálogos entre os sujeitos do campo, juntamente com outros de outros espaços, possibilitando outros saberes.

Atualmente vivemos em uma sociedade movida pela tecnologia, ao qual grande parte da nossa vida permeia em torno dessa. As tecnologias hoje servem para aproximar distâncias, melhorar a produção, agregar conhecimentos e outras inúmeras possibilidades. Neste contexto também é importante que os sujeitos do campo tenham conhecimento e acesso a esse avanço tecnológico, a fim de participarem ativamente da sociedade ao qual estão inseridos. Considerando que o ensino das escolas do campo deve ser adequado ao aluno do campo, também é importante ressaltar que os docentes precisam ainda inserí-los no meio tecnológico, propondo atividades que também contemplem essa descoberta do mundo tecnológico e que isto também sirva para libertá-los da posição de excluídos. 
Vivemos atualmente em tempos de cibercultura, que segundo Santos (2012, p. 161) é "a cultura contemporânea estruturada pelas tecnologias digitais em rede e vem se caracterizando atualmente pela emergência de mobilidade ubíqua (em todos os lugares) em conectividade com o ciberespaço e as cidades". Ainda conforme Santos

mobilidade, ubiquidade e conectividade podem propiciar às práticas pedagógicas, além da desvinculação do acesso às tecnologias via laboratório de informática, a imersão na cultura contemporânea, cibercultura, transformada por uma nova relação com o espaço e com o tempo, promovendo uma nova forma de estar em sociedade, permitindo, dessa maneira, que o aluno se movimente carregando, produzindo e cocriando informações e conhecimentos. (SANTOS, 2013, p. 289)

Essa afirmação leva-nos a refletir que estando nós inseridos no ciberespaço, espaço este caracterizado pela ubiquidade, torna-se imprescindível que também levemos essa ubiquidade a educação do campo e que o aluno do campo possa utilizar as tecnologias digitais de forma que venham a contribuir com a ampliação do seu conhecimento.

\section{Metodologia}

O estudo realizado procurou diagnosticar como os discentes entendem a sua trajetória enquanto aluno da escola do campo. Para levantar dados acerca disso foi realizada uma atividade de produção de relato em uma turma de alunos do $9^{\circ}$ ano. a atividade foi desenvolvida no aplicativo disponível na plataforma do Google, o Google Drive. Este aplicativo foi utilizado com a finalidade de aproximar os alunos das tecnologias digitais, visto que na atualidade o uso dessas ferramentas também fazem-se necessárias para o uso educacional.

A atividade foi desenvolvida a partir de questões como: a)Você acredita ter recebido uma educação direcionada à valorização do aluno do campo?b)O que você gostaria de ter aprendido e que não houve oportunidade?c)Você acredita que o que você aprendeu auxilia você a permanecer no meio rural?d)Você teve oportunidade de utilizar as tecnologias digitais no processo de ensino enquanto você foi estudante? Os discentes deveriam produzir um relato baseados nas questões solicitadas. $\mathrm{O}$ estudo foi realizado com cinco alunos do nono ano do Ensino Fundamental de uma escola localizada em um assentamento rural da Reforma Agrária. Estes docentes realizaram todo o Ensino Fundamental nesta mesma instituição de ensino. A faixa etária dos alunos está entre quinze e dezessete anos. Na próxima seção analisaremos os dados coletados.

\section{Discussão dos Resultados}


Os participantes foram identificados por números de um a cinco, a fim de apresentar melhor os resultados. O aluno 1 relatou que na sua vida estudantil teve uma boa aprendizagem tanto sobre o campo como sobre a cidade. Também acredita ter recebido uma educação direcionada ao aluno do campo, levantando afirmações acerca da disciplina de Técnicas Agrícolas, onde o professor os ensinava a lidar com o solo. Porém no que diz respeito ao uso das tecnologias digitais, salientou que a escola não proporcionou momentos relacionados à aprendizagem para que estas fossem utilizadas, uma vez que a escola não possui laboratório de informática e o uso do celular na maioria das vezes não é autorizado. Assim, o aluno também salientou que gostaria de ter aprendido mais com o uso das tecnologias na escola.

Ao analisar o relato do aluno 1 podemos concluir que para esse aluno a escola do campo foi relevante na sua aprendizagem, no entanto entende-se que poderia ter havido uma maior interação com o uso das tecnologias digitais no processo de ensino e de aprendizagem. Neste sentido cabe salientar que "a história, a economia, a política, a cultura, a percepção, a memória, a identidade e a experiência estão todas elas hoje mediadas pelas tecnologias digitais" (Santaella, 2013, p. 93). Desta forma, é relevante que estas tecnologias se façam presente na educação, inclusive na educação do campo.

O aluno número 2 apontou que a aprendizagem no campo foi tranquila, mas frágil para quem quer continuar os estudos. Neste sentido, para Caldart (2002, p. 22), os processos formativos das escolas do campo devem ir "desenhando outros traços em nossa identidade, fruto da síntese cultural a que nos desafiamos em conjunto", ou seja, não nos limitar aquilo que já sabemos; o que para esse aluno ficou notável quando fez essa assertiva. O discente salientou que na escola o acesso às tecnologias é difícil, não sendo estas utilizadas como ferramentas de ensino e de aprendizagem. Acredita que, em parte, recebeu uma aprendizagem direcionada ao campo quando cita como exemplo a horta que a escola possui, local onde os alunos plantam e os produtos colhidos são utilizados na merenda escolar. $\mathrm{Ou}$ seja, para esse discente a construção e participação nas atividades realizadas na horta da escola para ele serviram para aprender algo que está relacionado à sua atividade enquanto morador da zona rural.

O discente 3 considerou que a escola do campo contribuiu para que continuasse seus estudos em outra instituição de ensino, uma vez que citou que o aprendizado no ensino Fundamental irá colaborar para a sequencia de estudos do Ensino Médio. Porém este aluno não enfatizou nenhum item relacionado ao viver no campo. Isto leva-nos a concluir que para esse sujeito a vida no campo não é algo relevante, fato esse que pode ter relação com o 
currículo da instituição de ensino, se este não primar por um ensino direcionado às especificidades do aluno do campo. No entanto, o relato do aluno foi muito breve, levando em consideração só a aprendizagem com fim para a continuidade do conhecimento. Nesse sentido Fernandes afirma que

as áreas rurais não são lugares que só se produzem com a agropecuária ou caracterizadas pelo latifúndio, mas também um espaço e território de camponeses e de quilombolas. Por tudo isso, o campo é lugar de vida e, sobretudo, de educação. (FERNANDES, 2004, p.109)

A escola precisa estar atenta, fornecendo adequações necessárias às peculiaridades do público que atende, sendo que para o discente da educação do campo a Lei de Diretrizes e Bases-LDB 9.394/96, em seu artigo 28, responsabiliza os sistemas de ensino pela adequação da Educação Básica às diversas regiões das áreas rurais, de modo a propiciar condições para o pleno atendimento aos reais interesses e necessidades da população rural. A ideia ainda é complementada com a Constituição Federal em seu artigo $5^{\circ}$ que afirma que "todos são iguais perante a lei”. Cabe aí uma reflexão sobre o currículo e sobre as práticas docentes, considerando que educação está sendo oferecida ao meio rural e que concepção de educação do campo tem o docente que atua nas escolas do campo.

O aluno 4 afirmou que não recebeu uma educação direcionada ao campo, ressalta ainda que estudou vários conteúdos, no entanto não falavam nem eram direcionados à vida no campo. Caldart $(2002$, p. 23) defende a construção de pedagogias "que forme e cultive identidades, auto-estima, valores, memória, saberes, sabedoria; que enraíze sem necessariamente fixar as pessoas em sua cultura, seu lugar, seu modo de pensar, de agir, de produzir". O discente destacou ainda que gostaria de ter aprendido mais sobre o campo, uma vez que não pretende continuar os estudos e sim, trabalhar no campo e dali retirar o seu sustento. Destarte, para esse aluno seria imprescindível uma educação voltada para os afazeres da vida rural. Salientou ainda que as tecnologias não são usadas na escola.

$\mathrm{O}$ aluno 5 considerou que enquanto aluno, a sua aprendizagem em relação a vida no campo não o ajudou em nada. Afirmou que gostaria de ter aprendido na escola como conduzir um plantação na lavoura e fazer o plantio correto de árvores, visto que também pretende permanecer no campo e dali retirar o seu sustento. Mais uma vez fica notável a necessidade de uma educação que contemple as especificidades da zona rural. A cerca disso Arroyo enfatiza que

sem as matrizes que se formam sem entender a terra, o território e o lugar como matrizes formadoras, não seremos capazes de tornar a escola um lugar de formação. A articulação entre o espaço da escola e outros espaços, lugares, territórios onde se 
produzem, será difícil sermos mestres de um projeto educativo. (ARROYO, 2010, p.3)

A compreensão da especificidade desses vínculos entre território, terra, lugar, escola é um dos componentes da especificidade da formação de educadoras e educadores do campo. No campo é onde se concentra o maior número de professores que não participam de formação continuada prejudicando os discentes com suas práticas pedagógicas.

\title{
5.Considerações Finais
}

A educação no campo ainda é um assunto que vai estar por longos tempos nos espaços de discussões. A cultura dos povos do campo tem uma trajetória de esquecimentos histórica por parte do sistema educacional que compõem suas diretrizes alicerçadas aos interesses das classes dominantes. Conforme Souza

\begin{abstract}
A escola está amarrada ao modelo de sociedade, ao domínio de habilidades para competir no mundo do trabalho. Embora, atualmente, já nem existam empregos com carteira assinada para todos [...]. Repensar o modelo é um desafio para quem busca analisar a estrutura existente para saber como contrapor ao modelo, de maneira que se consiga propor novas e melhores alternativas de sociedade e de escola. (Souza, 2007, p. 27 e 28$)$
\end{abstract}

Nesse sentido, esta luta pela inserção dos valores, da identidade, dos saberes e da cultura dos povos do campo no currículo escolar é relevante para que a articulação de práticas pedagógicas tenham como base também as especificidades do povo do campo para serem aplicadas por quem de verdade tem responsabilidade por materializar o currículo, que são os educadores. Consoante a isto os projetos educativos relacionados à educação rural devem ser pensados numa perspectiva crítica, levando em consideração que o currículo direcionado às escolas inseridas no contexto rural contemplem requisitos que façam sentido para quem vive ou deseja ficar no campo e que estes espaços de formação também abranjam conteúdos que não torne o aluno da zona rural excluído, mas sim parte do processo de ensino, considerando a evolução da sociedade contemporânea, sejam evoluções de cunho tecnológico ou cultural.

\section{Referências}

ARROYO, Miguel G. Ofício de Mestre: imagens e auto-imagens. 12 ed. Petrópolis, RJ: Vozes, 2010

BRASIL. Ministério da Educação. Secretaria de Educação Continuada, Alfabetização, Diversidade e Inclusão - SECADI. Educação do Campo: marcos normativos/Secretaria de Educação Continuada, Alfabetização, Diversidade e Inclusão - Brasília: SECADI, 2012

BRASIL.Constituição(1988). Constituição: República Federativa do Brasil. Brasília, DF: Senado Federal, 1988. 
BRASIL. Lei de Diretrizes e Bases da Educação Nacional n.9394, de 20 de dezembro de 1996. Estabelece as diretrizes e bases da educação nacional. Publicada no Diário Oficial da União, Brasília, DF, 23 dez. 1996.Seção 1,p.27833-27841

CALDART, Roseli Salete. Por Uma Educação do Campo: traços de uma identidade em construção. In: KOLLING, Edgar Jorge; CERIOLI, Paulo Ricardo; CALDART, Roseli Salete (Orgs.). Educação do Campo: identidade e políticas públicas. Brasília, DF: Articulação Nacional Por Uma Educação do Campo, 2002.

CALDART. Roseli Caldart. Formação de Identidade. Pedagogia da Terra. Veranópolis, RS: ITERRA, 2002

FERNANDES, Bernardo Miguel.;CERIOLI, Paulo Ricardo; CALDART, Roseli Salete. Primeira Conferência Nacional "Por uma Educação do Campo. Petrópolis:Vozes,2004.

MOLINA,Mônica Castagna; JESUS, Sônia Meire Santos Azevedo de. (Orgs.) Contribuições para a construção de um projeto de educação do campo. Brasília, DF: Articulação Nacional por uma educação do campo, 2004. (Coleção por uma Educação do Campo, no 5.

GRITTI, Silvana Maria. Educação Rural e Capitalismo. Passo Fundo. UPF, 2003

PINTO, Luis Guedes. No censo agropecuário, mais concentração e exclusão. Valor Econômico. www.valoreconômico.com.br Acesso em 29/08/2018

SANTAELLA, Lúcia. Comunicação Ubíqua: repercussões na cultura e na educação. São Paulo: Paulus, 2013.

SANTOS, Edméa Oliveira; SANTOS, Rosemary Santos. Cibercultura: Redes Educativas e Práticas Cotidianas. Revista Eletrônica Pesquiseduca - p. 159-183, v.04, n. 07, jan.-jul.2012.

SANTOS, Edméa. WEBER, Aline. Educação e cibercultura: aprendizagem ubíqua no currículo da disciplina didática. Rev. Diálogo Educ., Curitiba, v. 13, n. 38, p. 285-303, jan./abr. 2013.

SOUZA, Eloir José de. Limites e possibilidades para a construção do Projeto Político Pedagógico da escola de Educação infantil e Ensino Fundamental Nossa Senhora Aparecida. Trabalho de Conclusão de Curso de Pedagogia - UERGS/ ITERRA: Veranópolis, 2007. 